\title{
Evaluating Flight Instructor Perceptions of Light Sport Aircraft
}

\author{
Timothy Harbeck, Jennifer Kirschner, and Bernard Wulle \\ Purdue University \\ Erin Bowen \\ Embry-Riddle Aeronautical University
}

\begin{abstract}
The Federal Aviation Administration has forecasted tremendous growth in general aviation over the next 20 years, mostly due to large increases in the population of sport pilots. These future pilots will need to be taught by instructors who have the experience, interest, and appropriate attitudes to accommodate successful growth in light sport aviation. Flight instructors without a sport pilot rating are authorized to instruct in light sport aircraft but have little or no experience requirements with such aircraft before teaching. The purpose of this study was to determine the perceptions current instructors held about light sport aircraft. This was accomplished by surveying two different samples of certified flight instructors: a group of randomly selected flight instructors from the FAA national airmen database, and a sample of flight instructors registered with the National Association of Flight Instructors. Instructor perceptions about light sport aircraft are analyzed using statistical methods. Comments indicate a need for additional effort to ensure the delivery of safe, efficient, quality training in light sport aviation.
\end{abstract}

\section{Introduction}

Light sport aircraft (LSAs) have quickly increased in popularity over the past few years. Their relatively low cost, lower fuel burn, and decreased experience requirements make them attractive to both flight schools and private owners. Additionally, the increase in flight time required before applying to a regional airline first officer position has many pilots looking for an inexpensive way to build flight time. There are 6,528 active LSAs operating in the country, compared to 222,520 active general aviation aircraft (Federal Aviation Administration, 2012), but most flight instructors do not have an LSA-specific license. How effective do non-sport pilot flight instructors feel they could be in light sport aircraft, and what attitudes do they have about LSAs? The present study intended to begin to address these questions in support of the growth of the light sport license among general aviation pilots.

In September of 2004, the Federal Aviation Administration (FAA) created a new category of aircraft to be flown by a new type of pilot. This was not the first time the FAA attempted to create more interest in aviation by adding an additional license category: the recreational pilot certificate introduced in 1989 (Experimental Aircraft Association, 2007a) was a dismal failure, peaking in 1999 with a total of 343 pilots (GAMA, 2006). The recreational pilot certificate required slightly less training than a 
traditional private pilot certificate, but with substantial restrictions to its use (“Certification: pilots, flight instructors, and ground instructors,” 2007). The light sport rule, however, was envisioned to fill a previously untapped market - aircraft too heavy to be unregulated ultralights, and too light to qualify as heavily regulated normal category aircraft. Examples of light sport aircraft include wood and fabric planes built in the 1930s and 1940s and newer all-composite models (Experimental Aircraft Association, 2007c). The overall effect of this ruling was twofold: it increased safety in a previously unregulated area of aviation, and it provided a path to licensure for a previously untapped population of potential pilots.

Along with a new aircraft category, the light sport rule also created a new section of airmen certificates. As with the aircraft, the new requirements for sport pilots exceed those of ultralight pilots, but are less than those of private pilots who fly normal category aircraft (“Ultralight vehicles,” 2001).. Two key differences exist between private pilot standards and sport pilot standards: the minimum required experience for sport pilots is half that of private pilots, and sport pilots may use a driver's license as certification of medical standards in lieu of the medical certificate required of private pilots, as long as they have never failed a pilot medical examination. Since the holder of a higher certificate may exercise the privileges of a lower certificate, holders of a recreational, private, commercial, or airline transport pilot certificate who have allowed their FAA medical certificate to expire can fly again, as long as they hold a driver's license and comply with any relevant restrictions, such as wearing glasses. This reduction in requirements comes with a reduction in privileges, which will be explained in the next section(Federal Aviation Administration, 2004).

\section{Light Sport License Characteristics}

While the requirements to exercise sport pilot privileges are greatly reduced from those of private pilots, the privileges are also greatly reduced. Sport pilots are limited to personal flying in aircraft that weigh no more than 1,320 pounds on land or no more than 1,430 pounds on water. LSAs are limited to a single reciprocating engine; although there is no restriction on horsepower, the weight restriction effectively limits the horsepower of the aircraft. Sport pilots are prohibited from flying at night, flying for business, carrying more than one passenger, flying without reference to the ground or with less than 3 miles of visibility, flying internationally, flying above 10,000 feet, towing an object, or flying through class B, C, or D airspace without additional training. Sport pilots are prohibited from flying an aircraft that has a Vh speed (maximum speed in level flight with maximum continuous power) faster than 87 knots without additional training. Even after receiving additional training, they can fly no aircraft with a Vh speed of more than 120 knots ("Certification: pilots, flight instructors, and ground instructors," 2007; "Definitions and abbreviations," 2006). Effectively, sport pilots are limited to pleasure flying in good weather. 
Despite these strict limitations, the sport pilot certificate has been much more successful than the recreational pilot certificate. The number of sport pilots is already much higher than the peak number of recreational pilots, with 134 sport pilots after the first year and 939 at the end of 2006. This well exceeded the previous forecast of 300 sport pilots by the end of 2006 (GAMA, 2006). Further growth is projected to 12,800 sport pilots in 2015 and 20,600 sport pilots in 2025 (Federal Aviation Administration, 2008a).

Registered LSA are expected to grow from the 170 registered in 2005 to 13,200 aircraft by 2020 (Federal Aviation Administration, 2007b). Many of the first LSA registered were previously-built two-seat ultralights operating under an FAA exemption. These aircraft had until January 31, 2008 to be grandfathered into the light sport rule with experimental light sport aircraft (E-LSA) airworthiness certificates ("Certification procedures for products and parts,” 2007). After this date, all new LSA were given special light sport aircraft (S-LSA) airworthiness certificates. Industry predictions call for about 10,000 new S-LSAs to be manufactured by 2020. The actual number of aircraft meeting LSA restrictions to be produced will be even higher, because this number does not account for aircraft certified under standard and experimental aircraft categories, which meet the definition of an LSA. A listing of possible experimental aircraft that meet the LSA definition is available from the EAA (Experimental Aircraft Association, 2007b). Variances in experimental aircraft and the airworthiness status of vintage aircraft make the exact number of aircraft meeting the technical requirements to be classified as an LSA unknown. Regardless, the growing number of sport pilots will have an increasing selection of aircraft.

Aircraft availability, however, is not the only factor driving the growth in recreational aviation. Growth is coming because a sport pilot certificate is easier to obtain and available to a larger number of people. After the failure of the recreational pilot certificate category, the FAA recognized that any new type of licensure would have to be significantly different from previous categories in order to generate interest. A new category of pilots, however, necessitated a new type of flight instructor.

\section{Instructing in Light Sport Aircraft}

Until 2004, certified flight instructors (CFIs) could only be certificated under 14 CFR 61 subpart H. Afterward, subpart K created a new class of flight instructors (CFI-SPs) to teach newly licensed sport pilots ("Certification: pilots, flight instructors, and ground instructors,” 2007). The requirements to be a CFI far exceed the requirements to be a CFI-SP, but the current regulations do not require CFIs to receive any flight or ground training pertaining to light sport aviation. While the requirements for CFI-SPs are much lower, the privileges granted are lower as well. CFI-SPs can only train sport pilots, while CFIs can instruct recreational, private, and commercial pilots in a light sport aircraft with no additional training, and can instruct sport pilots with just 5 hours of experience in a similar LSA (Federal Aviation Administration, 2004). 


\section{Certified vs. Experienced Instructors}

As Reinhart (1990) has suggested, simply being legal in an aircraft does not assure that a pilot is either safe or an effective flight instructor. Upon receiving the certificate, most instructors are advised that it is a "license to learn" and are encouraged by FAA publications to find an experienced flight instructor to mentor them (Federal Aviation Administration, 2007a). CFIs need many traits to successfully provide quality training to sport pilot students.

The FAA requires flight knowledge, skills, and experience to obtain a flight instructor certificate, but much more than that is needed to be a good instructor. In addition to being qualified, an instructor must be properly motivated. FAA instructional publications (1999) report improved effectiveness of intrinsically motivated instructors is due to an enhancement in the principle of effect. This principle states that learning is enhanced when associated with pleasant and enjoyable feelings, and conversely learning is weakened when accompanied by negative feelings (Federal Aviation Administration, 1999). This is especially important in recreational aviation, where even on a training flight an objective of the flight is enjoyment. A study of instructor effectiveness in kayaking by Phipps and Claxton (1997) revealed other issues in a similarly complex, high-risk activity, including the negative impact of showing too much risk too soon when instructors perform advanced maneuvers that beginning students cannot yet handle. Those experiences could frighten and turn students away.

Similarly, studies by Block (2007) focused specifically on the method individual instructors used to teach. More experienced instructors were more aware of basic teaching considerations, but many instructors were not motivated to improve their teaching methods - they saw teaching as a path to other employment in aviation, not an end goal. Their students took longer to progress, as a result. Additionally, instructors used to flying and teaching in more complex aircraft will need to make adjustments to teaching in a LSA, a type of "backward transition" made when transferring from more complex aircraft to simpler aircraft (Wiener, Chute, \& Moses, 1999). Instructors will need to avoid the complacency that could be induced by flying a "simpler" aircraft. Even though the aircraft are simpler, their performance characteristics could be very different from any other aircraft the instructors have flown.

In summary, sport pilots and LSA represent an exciting new direction for aviation. More people than ever before are eligible to begin flight training, and all general aviation pilots have an increasing selection of low-cost aircraft from which to choose. In order for this renewed interest in aviation to continue, however, training in LSA must be just as safe and enjoyable for pilot applicants as training in typical aircraft has been, if not more so, as additional emphasis is placed on flying for enjoyment with light sport pilots. Instructors must be able to provide safe, comfortable learning experiences to their students (Federal Aviation Administration, 2008b). 
Although a new category of instructors has been created, most instructors are currently licensed as CFIs, not CFI-SPs. CFIs are authorized to instruct in light sport aircraft with little to no experience in them, but these LSA may be very different than any other aircraft that they have flown. Do current CFIs feel comfortable flying and/or instructing in LSA? If the new light sport certificate is to be successful in the long-term, new light sport pilots need confident, knowledgeable instructors who are not only legally qualified to instruct light sport, but willing and eager to do so. In order to examine whether current instructors are indeed comfortable flying/instructing LSA, two samples of current CFIs were asked about their attitudes toward typical primary training aircraft and toward LSA.

\section{Methodology}

This research study used an online survey to measure attitudes of current CFIs about light sport aviation. This was thought to be more convenient for the sample population and greatly facilitated dissemination and data analysis, providing an overall more efficient use of time and resources for all parties involved. Participants were informed that their responses would be kept confidential, and that the data would only be referred to in the aggregate.

The variables measured included demographic information, attitudes, and perceptions of effectiveness. In order to compare instructor views of LSAs as opposed to more traditional/typical primary training aircraft such as the C-172 or Piper Warrior, instructors were asked about their level of comfort in typical small aircraft and in LSAs. Responses for each question were then averaged and subtracted to show the mean difference. Before use, the survey was validated by pilot testing and a thorough review by the Light Sport Aviation Branch of the FAA and the executive director of the National Association of Flight Instructors (NAFI).

In order to sample CFIs with different backgrounds, two different groups were used: a sample of licensed flight instructor addresses available from the FAA, and a sample of flight instructors who subscribe to the NAFI electronic newsletter. The NAFI flight instructors were thought be to more active in flight instruction and perhaps more familiar with light sport aircraft, and so provided an appropriate comparison to FAA-database instructors. A postcard with a link to the online survey was sent to a simple random sample of 1,000 ASEL and/or ASES CFIs and CFIIs (out of 77,591 registered with the FAA). This mailing generated 69 responses, a rate of 6.9\%. Concurrently, a hyperlink to the survey was included in the NAFI electronic newsletter E-mentor, accessible to the entire readership of approximately 4,000 CFIs. Of the 163 responses, one participant was not a flight instructor and was removed, giving a true response rate of $4.05 \%$. The surveys were open for four weeks. Both surveys had identical content, but used different links to differentiate between the responses. This low response rate was in keeping with that found by authors of similar mail-based studies (Dillman, 2000), but for the purpose of this initial exploratory study of light sport instructors it generated an appropriate sample size. Future studies on a larger scale are warranted, based on initial findings 
described herein.

\section{Results}

\section{Demographics}

Flight instructors who responded from the FAA database were mostly white (98\%) males (97\%), with large numbers of instructors in their 30s and in their 60s. The average age was 48.7 years, with a minimum of 21 and a maximum of 78 . Half of flight instructors (52\%) identified themselves as active flight instructors, and a quarter (26\%) reported having flight time in light sport aircraft. Only two participants (3\% of those who responded) were registered with the Experimental Aircraft Association (EAA) as sport pilot instructors (instructors licensed under subpart $\mathrm{H}$, but who are willing to provide light sport instruction). The full EAA database has 902 sport pilot instructors on file, or $1.37 \%$ of CFIs with ASEL privileges.

NAFI flight instructors were also split between instructors in their 20s and 30s, and instructors in their 60s, with a minimum of 22 and a maximum of 83: The average was 53.3. The population was again mostly white $(95 \%)$ males (96\%) who consider themselves active flight instructors (90\%). A large number (21.25\%) were registered with the EAA as sport pilot instructors licensed under subpart $\mathrm{H}$, including one who reported having a sport pilot flight instructor certificate (licensed under subpart K). A readership of 4,000 meant that, statistically, $1.37 \%$ or 55 sport pilot instructors should have seen the link, of which 34 (61.8\%) responded. This response rate is much higher than for sport pilot instructors culled from the FAA database, possibly due to a lower number of sport pilots included in the simple random sample than in the NAFI sample, or due to a greater proportional concentration of sport pilot instructors in the NAFI sample than in the larger FAA database.

\section{Attitudes toward Typical Primary Training Aircraft}

Participants were first asked about their attitudes towards typical primary training single-engine aircraft in order to establish a baseline of self-ratings. A five point Likerttype scale was used; a selection of one indicated "no experience from which to judge," while two through five corresponded to Strongly Disagree, Disagree, Agree, to Strongly Agree, respectively (depicted as NE, SD, D, A, and SA in the figures). Responses across both groups were very similar, with slightly more variation in the ratings of flight instructors listed in the FAA database, possibly due to a wider range of flight experiences. The average ratings for both groups were also very similar. Open-ended responses indicated that many who rated their attitudes toward primary training single-engine aircraft as uncomfortable or unenjoyable (see specific survey items in Figures 1-5) felt so due to issues such as lack of currency or unwillingness to lose access to the more sophisticated equipment found in larger aircraft. In addition, some respondents reported they would not feel comfortable teaching in typical primary-flight training as they thought they would become bored with "pattern work" - flying a 
relatively monotonous pattern with a more basic student.

\section{Attitudes toward Light Sport Aircraft}

The next section of the survey asked the same five questions as previously described, though now regarding light sport aircraft rather than typical primary training singleengine aircraft; see Figures 1-5 for these responses and survey questions. Again, both the FAA and NAFI groups have very similar positively-skewed responses, with similar percentages of instructors selecting "no experience from which to judge" and either "agree" or "strongly agree."

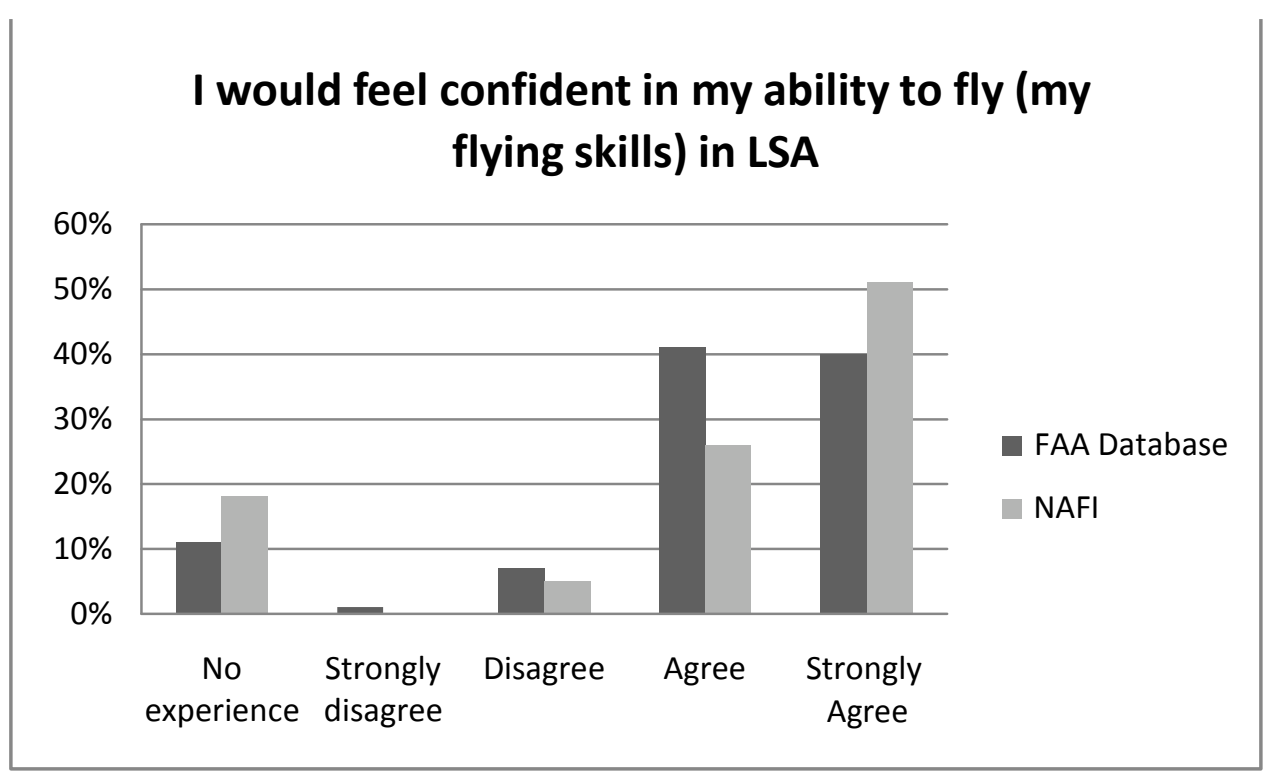

Figure 1. Responses from instructors selected from the FAA database and NAFI registered instructors to the statement "I would feel confident in my ability to fly these aircraft.” 


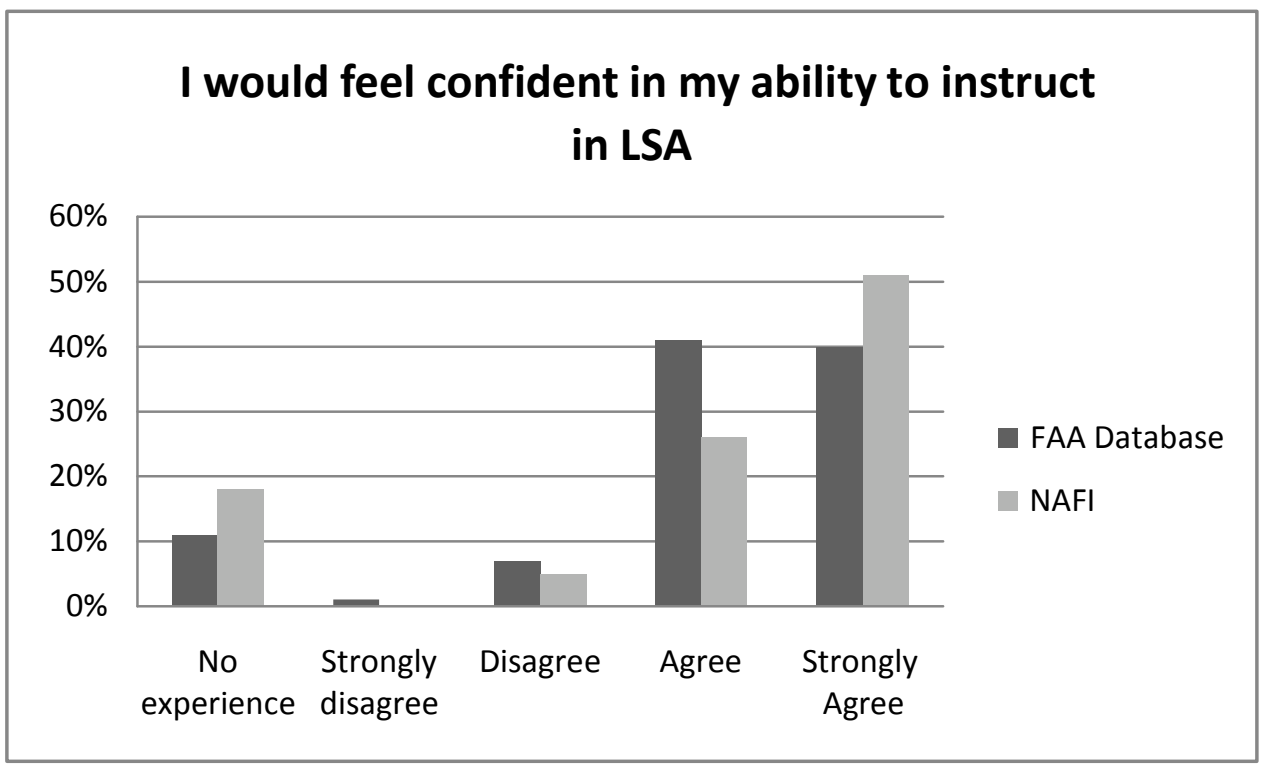

Figure 2. Responses from instructors selected from the FAA database and NAFI registered instructors to the statement "I would feel confident in my ability to instruct in these planes.”

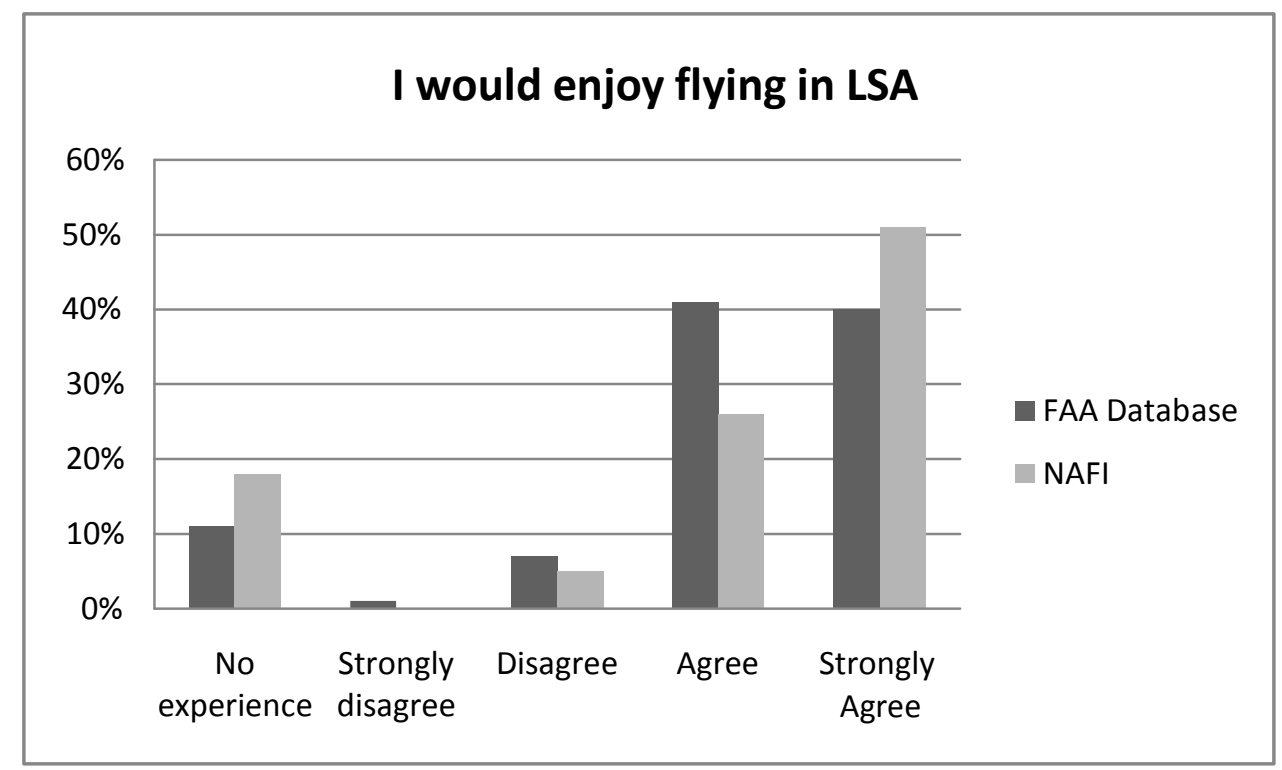

Figure 3. Responses from instructors selected from the FAA database and NAFI registered instructors to the statement "I would enjoy flying in these aircraft." 


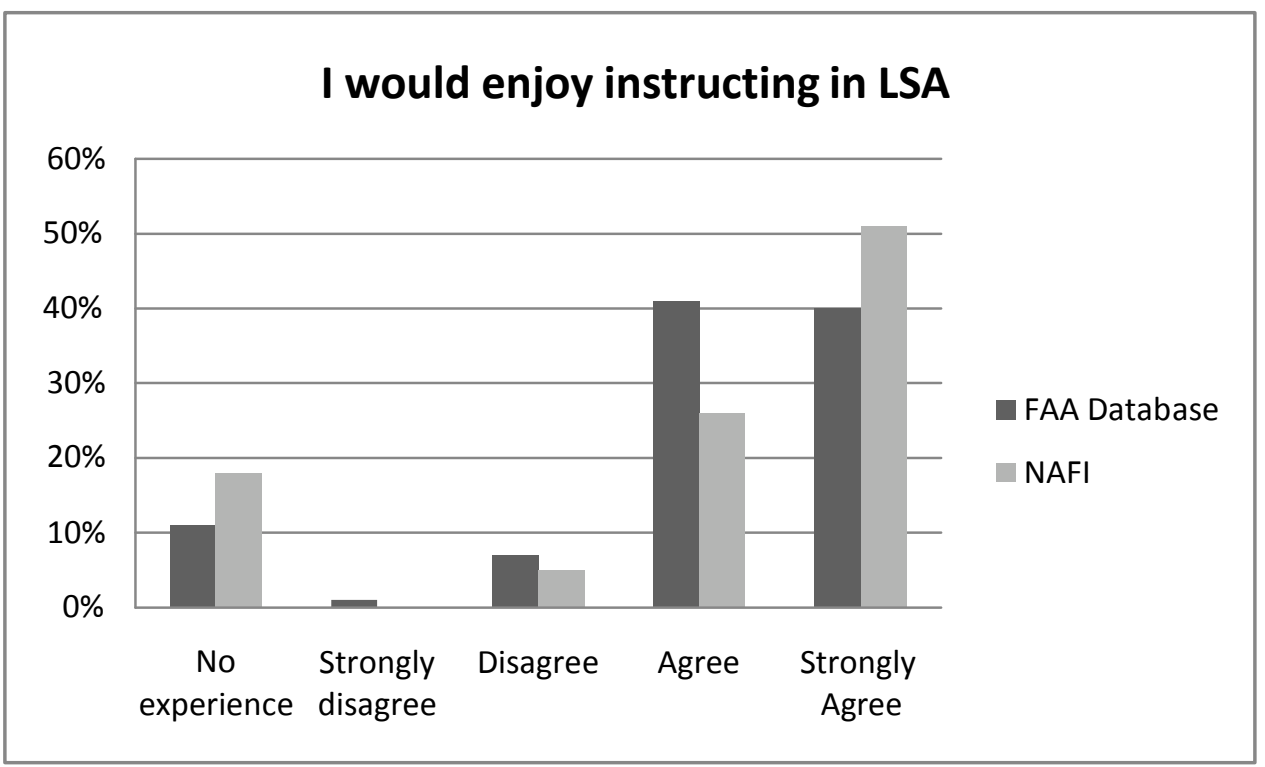

Figure 4. Responses from instructors selected from the FAA database and NAFI registered instructors to the statement "I would enjoy instructing in these aircraft."

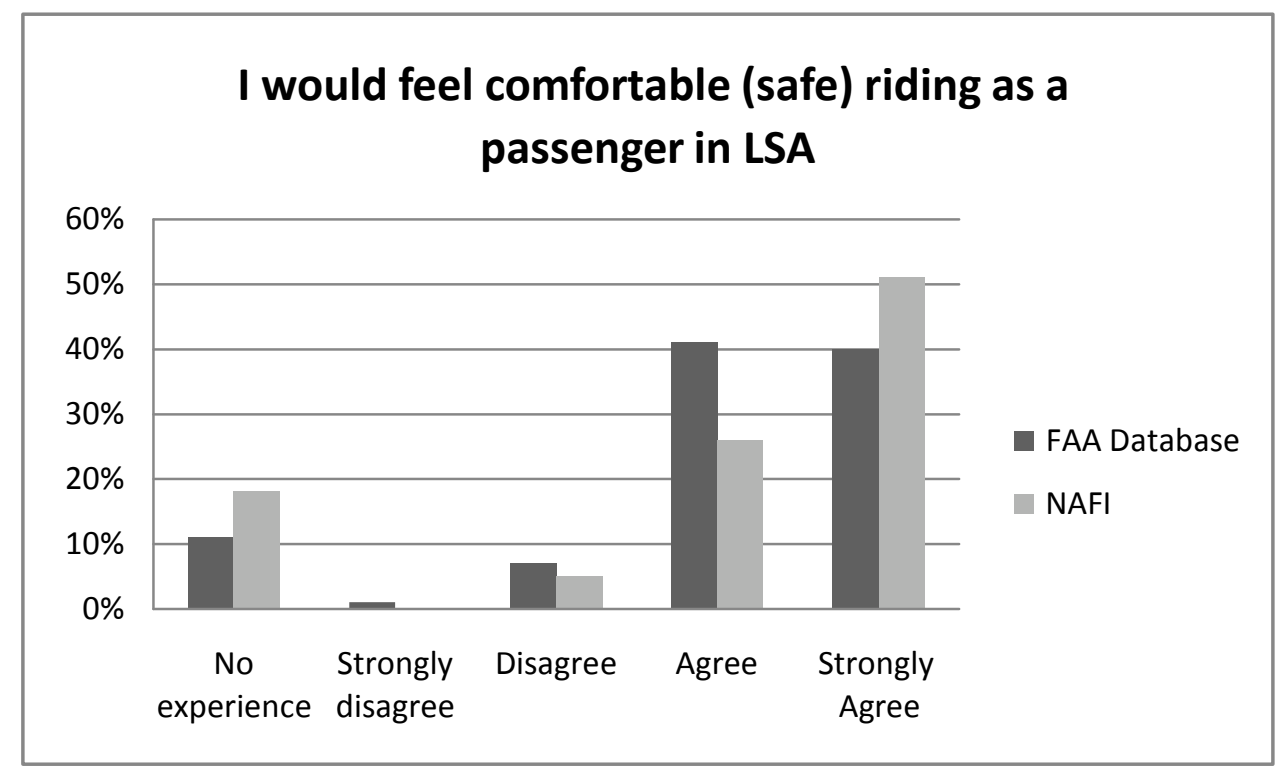

Figure 5. Responses from instructors selected from the FAA database and NAFI registered instructors to the statement "I would feel comfortable (safe) riding as a passenger in these aircraft.”

Open-ended responses regarding the LSA ratings showed the importance of using the difference in averages instead of directly comparing survey responses. Some pilots who reported owning LSAs rated themselves very low, while others who had never flown LSAs thought they would make good instructors "after gaining familiarity and endorsements." Some reported their rating of safety and comfort to be largely dependent on the pilot with whom they were flying. 


\section{Differences between LSAs and Typical Training Aircraft}

In order to examine how LSAs compared to typical primary training aircraft, the average ratings from each of the five questions for typical training aircraft were subtracted from the average rating of each of the five questions for LSAs. This mean difference for the five questions and for the average overall response is shown in Table 1. The scored differences show that LSAs were rated lower (mean $=-0.811$ for FAA registered instructors and -0.841 for NAFI registered instructors) than typical training aircraft, regardless of the instructor's background. It is unusual to note that, while the NAFI- registered flight instructors had more experience in LSAs and a greater concentration of LSA instructor pilots, they actually rated their perceptions and comfort with LSAs as worse than the flight instructors who reported minimal experience with LSAs.

\begin{tabular}{|c|c|c|c|c|c|c|}
\hline $\begin{array}{c}I \\
\text { would... }\end{array}$ & $\begin{array}{c}\text { feel safe as } \\
\text { a passenger }\end{array}$ & $\begin{array}{c}\text { feel comfortable } \\
\text { flying }\end{array}$ & $\begin{array}{c}\text { feel comfortable } \\
\text { instructing }\end{array}$ & enjoy flying & enjoy instructing & $\begin{array}{c}\text { Overall } \\
\text { Mean } \\
\text { Difference }\end{array}$ \\
\hline FAA & -0.800 & -0.754 & -0.967 & -0.656 & -0.885 & $\mathbf{- 0 . 8 1 1}$ \\
\hline NAFI & -0.822 & -0.848 & -0.945 & -0.740 & -0.855 & $\mathbf{- 0 . 8 4 1}$ \\
\hline
\end{tabular}

Table 1. Average rating difference for FAA database flight instructors and NAFI registered flight instructors.

\section{Discussion}

LSA are becoming increasingly common over time, as manufacturers tap into a previously undiscovered market. These new aircraft will require additional instructors to train both sport pilot applicants, and recreational, private, and commercial pilots in light sport aircraft.

This study gathered self-rated perceptions about typical training aircraft and LSAs from two national samples of flight instructors in order to determine the extent to which CFIs are prepared to instruct in light sport aircraft. Regional differences could not be compared due to the small number of participants. As such, the findings of this study are broader, describing general perceptions that apply to the larger population of flight instructors. Most (70\%) reported no experience in LSA; in spite of this, CFIs rated their perceptions of their abilities to instruct in these aircraft highly. The lack of experience that most instructors reported, combined with a high perception of their ability to instruct in LSA, points toward a larger issue. What competencies are important to assess in flight instructors before they initially instruct in LSA? Because of the diversity in aircraft that could potentially be classified as LSA, it is largely left to the individual instructor to determine what, if any, additional training or practice should be conducted beyond that required by the FAA.

Further research in light sport instruction is necessary to better understand how to best 
prepare future sport pilots. Gathering feedback from recent sport pilot applicants would allow researchers to gain valuable insight into specific competencies or skill sets that require additional reinforcement from instructors. Other subpopulations that should be explored are EAA registered sport pilot instructors and CFI-SPs, in order to assess how well-prepared all instructors are for light sport instruction.

\section{Biographical Sketch - Timothy Harbeck}

Timothy Harbeck was a leading student in the Professional Flight Program in Purdue University's Department of Aviation Technology. Upon completion of his undergraduate degree and acceptance of a first officer position with a commercial airline, Harbeck was diagnosed with incurable brain cancer. Desiring to use his remaining time to assist others in the aviation field, Harbeck began work on a master's degree in aviation at Purdue, as well as teaching undergraduate courses in the field. The present article is adapted from his master's thesis project, completed six months before his death. Harbeck continues to be an example of integrity and courage for his students, peers, and the faculty who worked with him. 


\section{References}

Block, E. J. (2007). An analysis of factors involved in teaching pilots to land.(Unpublished doctoral dissertation). University of Minnesota, Minneapolis, MN.

Certification procedures for products and parts, 14 C.F.R. § 21 (2007).

Certification: pilots, flight instructors, and ground instructors, 14 C.F.R. $§ 61$ (2007).

Definitions and abbreviations, 14 C.F.R. $\S 1.1$ (2006).

Dillman, D. A. (2000). Mail and internet surveys: The tailored design method (2nd ed.). New York, NY: John Wiley \& Sons.

Experimental Aircraft Association. (2007a). Experimental aircraft association chronology. Retrieved from http://www.airventure.org/2007/media/EAA_ chronology.pdf

Experimental Aircraft Association. (2007b). Likely candidates for light sport aircraft. Retrieved from http://www.sportpilot.org/learn/lsa/likely_lsa.html

Experimental Aircraft Association. (2007c). Standard certificate aircraft. Retrieved from http://www.sportpilot.org/learn/lsa/standard_certificate_aircraft.html

Federal Aviation Administration. (2004). Certification of aircraft and airmen for the operation of light-sport aircraft. Retrieved from https:/www.federalregister.gov/articles/2004/07/27/04-16577/certification-ofaircraft-and-airmen-for-the-operation-of-light-sport-aircraft

Federal Aviation Administration. (2007a). Best practices for mentoring in aviation education. Retrieved from http://www.faa.gov/training_testing/training/media/mentoring_best_practices.pdf

Federal Aviation Administration. (2007b). FAA aerospace forecasts FY 2007-2020. Retrieved from https://www.faa.gov/data_research/aviation/aerospace_forecasts/20072020/media/ FORECAST\%20BOOK\%20SM.pdf

Federal Aviation Administration. (2008a). FAA aerospace forecasts FY 2008-2025. Retrieved from https:/www.faa.gov/data_research/aviation/aerospace_forecasts/20082025/media/ FAA\%20Aerospace\%20Forecasts\%202008-2025.pdf 
Federal Aviation Administration. (2008b). Aviation instructor's handbook. Washington, D.C.: Dept. of Transportation, Federal Aviation Administration.

Federal Aviation Administration. (2012). FAA Aerospace Forecast, Fiscal Years 20122032. Washington, D.C.: Federal Aviation Administration Aviation Policy and Plans.

GAMA. (2006). General aviation statistical databook (pp. 26-28, 38). Washington, D.C.: Author

Phipps, M. L.\& Claxton, D. B. (1997). An investigation into instructor effectiveness. The Journal of Experiential Education, 20(1), 40-46.

Reinhart, R.O. (1990). Compulsory retirement at Age 60. In, Challenges and choices in corporate aviation safety. Proceedings of the 35th annual corporate aviation safety seminar. Arlington, VA: Flight Safety Foundation, 12-17

Ultralight vehicles, 14 C.F.R. § 103 (2001).

Wiener, E. L., Chute, R. D., \& Moses, J. H. (1999). Transition to glass: Pilot training for high-technology transport aircraft. Flight Safety Digest, 18(6-8), 1-136. 